\title{
The Power of Meaningful Gestures in Teaching and Learning Literacy in Early Childhood Education Centres in the Cape Coast Metropolis
}

\author{
Lawrence Bosiwah $^{1}$, Joyce Esi Bronteng ${ }^{2}$ \\ ${ }^{1}$ University of Cape Coast, College of Humanities \& Legal Studies, Department of Ghanaian Languages and Linguistics, Cape Coast, Ghana \\ ${ }^{2}$ University of Cape Coast, College of Education Studies, Department of Basic Education, Cape Coast, Ghana
}

Email address:

lbosiwah@ucc.edu.gh (L. Bosiwah), esibrontengjoyce@yahoo.com (J. E. Bronteng)

\section{To cite this article:}

Lawrence Bosiwah, Joyce Esi Bronteng. The Power of Meaningful Gestures in Teaching and Learning Literacy in Early Childhood Education Centres in the Cape Coast Metropolis. International Journal of Elementary Education. Vol. 4, No. 3, 2015 , pp. 46-55. doi: $10.11648 /$ j.ijeedu.20150403.12

\begin{abstract}
Children come to school with emergent literacy which teachers need to build on to enhance early literacy acquisition in both the first language (L1) and the target language (L2) which in the case of Ghana is English Language. One of the supporting systems used to enhance effective teaching and learning is meaningful gestures such as iconic, metaphoric, deictic, and beat. The aim of the study is to find out how teachers use meaningful gestures to enhance effective teaching and learning of literacy in early childhood centres. Ten early childhood centres in the Cape Coast Metropolis in the Central Region of Ghana, consisting of 5 public and 5 private schools were selected. Observation and interviews were used for the data collection and analysed. The result indicated that most teachers use meaningful gestures only when they are teaching recitation. Little attention is paid to the use of gestures in other literacy lessons such as storytelling, reading, listening and speaking, and community circle time. Based on the findings, it has been recommended that early childhood education teachers should be educated on the use of meaningful gestures alongside speech in promoting early literacy acquisition.
\end{abstract}

Keywords: Meaningful Gestures, Emergent Literacy, Early Childhood Education, Multimodality

\section{Introduction}

Learning to read and write at a high level of proficiency is an on-going process, however, it is established that the early childhood years serve as a vital foundation for subsequent literacy development (Snow, Burns, \& Griffin, 1998; Whitehurst \& Lonigan, 2001; Vukelich, Christie \& Enz, 2012). This is in line with the assertion that, quality early childhood education programmes for young learners usually have long-lasting and positive consequences for children's success in school and later in life (Barnett, 1995; Frede, 1995). This means that the degree to which young learners acquire requisite literacy skills is mostly a strong predictor of future academic success (Collins, 2010; Gregory \& Cahill, 2010; National Reading Panel, 2000; IRA/NAEYC, 1998; Werner \& Smith, 1992) thereby making literacy the bedrock of other subjects. This implies that the success of education depends on the foundation young learners acquire from the Early Childhood Education (ECE).

Early childhood education (ECE) refers to the formal teaching of young children usually from age $0-8$ by people outside the family or in settings outside the home. It focuses on children learning through play. This belief is centered on the "power of play". It has been thought that children learn more efficiently and gain more knowledge through playbased activities such as dramatic play, art, and social games. Looking at the ages of pupils at the ECE, it could be seen that, most of the learners have low language skills especially at the initial part of their education thereby will need gestures (an aspect of multimodality) alongside verbal communication to enable them deal with what they hear and what they want to express to others, hence this study. The gestures we are dealing with in this study are not the everyday communicative gestures but the specific ones, which have to be clear and unambiguous in order to help pupils understand the verbal input the gestures illustrate.

The use of gestures is culturally oriented. Ghanaians, among other groups of people use gestures to express variety 
of feelings and thoughts, from contempt hostility to approval and affection. In Ghana, pointing of fingers can be expressed in so many ways. Using the right hand to point at something could mean that the person is showing a way or something, or wants people to look at something. Ghanaians normally use the right hand and not the left hand to point at something. It is inappropriate (a taboo) to use the left hand or finger to direct something or use it to eat (Crayner, 1969). If someone shows all the five fingers it means all hands are not equal. It is an indirect way of telling the society to avoid covetousness, and also to appreciate people the way they are and how they do their things because we are not the same.

In Ga, a child showing all the 5 fingers towards his/her friend is an insult. S/he is saying, "your mother" (Thus, insulting your mother's ass). In Akan, usually, children and sometimes villagers insult children, saying 'your mother' by folding the fingers and pressing the thumb up and down.

The use of gestures in schools emphasize on the positive usage. During instruction, teachers do not select insulting, taboo or offensive gestures but those gestures that are meaningful to the classroom teaching and learning. The study is guided by the multimodality approach to teaching and learning, as McNeil (1992) categorized as iconic, metaphoric, deictic and beat gestures. Teaching a rhyme like 'A lion' in a Ghanaian early childhood classroom for instance, requires the use of meaningful gestures (meaningful actions) alongside the sounding out of the words to make the words meaningful to the children who are English language learners (ELLs). By so doing, the teacher and the children would be describing how a lion looks like or the physical features of the animal through their recitation and they use gestures to show the part of the lion they are referring to. For example, when they say, "A lion, a lion, a lion has a tail (they pretend to have a tail and so they hold it at their back). It has a big head (they all touch their head) and a very small waist, and a very small waist (they hold their waist with their two hands and pretend pressing it in to make it small by shaking their waists). Such meaningful gestures alongside speech actually help pupils who are learning the English language in addition to their first language (as in the case of Ghanaian children) to understand concepts better.

A child at the ECE level of education understands things better when teachers use the combination of gestures and speech in their classroom communication. The reason is that, most of these pupils have not developed language enough to enable them communicate effectively with speech only. Therefore, the introduction of gestures alongside speech enhances communication since gestures convey additional meaning or information to the accompanying speech (Morford \& Goldin-Meadow, 1992; Stanfield, Williamson \& Özçalişkan, 2013).

The curriculum for most of the ECE centres in Ghanaian schools includes reading, recitation, storytelling, community circle time and listening and speaking. However, worship has indirectly become part of the education curriculum in Ghana, in that, almost all the basic schools in Ghana do worship on every Wednesday. On Wednesdays, before the school starts lessons, they all gather in a classroom and conduct 'church service'. They pray, sing, dance and listen to the word of God.

Storytelling plays a major role in Ghanaian culture and for that matter. People tell stories at home, at school, media, etc. Abdolmanafi-Rokni and Qarajeh (2014) explains storytelling as a creative art which entertains people over centuries and across cultures and its instructional potential continues to serve teachers. Storytelling is regarded as a comprehensive device because speakers use their background and linguistic knowledge to create a message that will be meaningful to the intended audience in all cases. Speakers activate relevant schemata from specific context to convey meaning for a definite purpose with an intended audience in mind. They further explained that storytelling helps speakers (1) to be able to comprehend meaning that is conveyed at a level beyond that of sentence, (2) to have a purpose, which is to bridge some information gap, (3) to have the choice of what to say and how to say it, (4) to have an objective in mind while talking and (5) to attend to many factors at the same time. They believe that storytelling helps students improve their speaking skills, their communication skills, their language knowledge, vocabulary, grammar, pronunciations, accent, etc. For this reason, teaching and learning of storytelling is more effective if accompanied with the use of meaningful gestures.

Another area of concern in Ghanaian culture which has gained root in the ECE curricula is community circle time. In the great majority of pre-school classes, the circle times is an activity that recurs daily, usually in the morning, but even at lunch or in the afternoon. Most children attending pre-school classes at some point experience and participate in a circle, perhaps with mixed feelings. Most children participate in the circle time and have their own ideas about its content. Circle time is thus the educational arena as differences in teaching methods may vary (Svensson, 2014) but it become more effective if the teaching goes with meaningful gestures.

\subsection{Statement of the Problem}

The quality of education young learners receive in their early years of schooling (ages 0-8) is often a critical indicator of their long-term academic success (Piaget, 1959). Research has shown that early literacy is crucial to future academic success and as such attention must be given to early literacy acquisition (Collins, 2010; Gregory \& Cahill, 2010; National Reading Panel 2000; Whitehurst \& Lonigan, 2001; Vukelich, Christie \& Enz, 2012). The importance of assisting young learners to acquire the appropriate literacy skills in the early childhood cannot be overemphasized. Learners at this stage of schooling do not have enough language for communication. This demands that other modalities be combined with verbal communication to enhance literacy comprehension. One such multimodal is the use of gestures. However, the use of gestures alongside speech in literacy instruction has not received the needed attention it requires in the ECE classrooms to assist young learners improve language skills, hence, this study. The study examines the extent to which ECE teachers in the 10 
selected schools in the Cape Coast Metropolis use gestures alongside speech in their literacy instruction to assist young learners in the acquisition of early literacy since it is the bedrock of other subjects.

\subsection{Purpose of the Study}

The main purpose of the study was to examine how teachers used gestures to enhance effective literacy instruction in early childhood centres in the Cape Coast Metropolis in the Central Region of Ghana. Specifically, the study was to:

1 find out the kind of experience ECE teachers have in teaching literacy;

2 identify the emergent literacy behaviours young children bring to school;

3 examine the extent to which gestures are used in the teaching of literacy in ECE, and

4 to find out how the use of gestures enhances teaching and learning of literacy in the classroom.

\subsection{Research Questions}

To achieve the above objectives, the following research questions were formulated to guide the study:

1 What experience do ECE teachers have in teaching literacy?

2 What emergent literacy behaviours do pupils bring to school?

3 To what extent are gestures used in the teaching of literacy in ECE?

4 How does the use of gestures enhance teaching and learning of literacy in the classroom?

\section{Literature Review}

The literature review focused on emergent literacy, the theoretical framework which is the multimodality approach to teaching and how gestures; as one of the modes of communication enhances comprehension of literacy in ECE.

\subsection{Emergent Literacy}

Literacy learning begins early in life and is ongoing. It does not wait for kindergarten or Basic one. Starting from infancy, the informal and playful things that adults do to promote children's language and literacy really count (Strickland, 2005). Due to this the children carry some emergent literacy to the classroom. Holtzheuser et al. (2012) define emergent literacy as the developmental period from birth through age six. Emergent literacy is 'the skills, knowledge and attitudes that are presumed to be developmental precursors to conventional forms of reading and writing' (Whitehurst \& Lonigan 1998: 849; NCCA, 2009:54). It is also said to be the literacy behaviours of children that precede conventional reading and writing. Emergent literacy suggests that the development of literacy takes place within the child in a gradual process. Holtzheuser et al. (2012) agree that as there has been an increasing focus on literacy among young children, there is not a specific point of time in life that literacy begins, but that at any point, children are in the process of becoming literate. It should be noted that for something to emerge it needs to be there at the beginning (the child's own natural learning ability), under the right conditions (Hall, 1987). Concern for quality pre-schools and developmentally appropriate activities support the importance of an understanding of emergent literacy (Freeman \& Hatch, 1989). One such developmentally appropriate practice is the use of appropriate gestures alongside speech which falls under multimodality approach (NCCA, 2012).

\subsection{Multimodality Approach to Teaching}

Multimodality is the mixture of textual, audio, and visual modes in combination with mediums and materiality to create meaning. According to National Council for Curriculum and Assessment (NCCA 2012), the term 'multimodality' describes approaches to representation that assume communication and meaning-making that are more than just a spoken or oral language. It takes into account the many different modes in printed and on-screen texts (such as image, layout, colour and language and also the different modes that people use as they engage in face-to-face interaction such as gesture, gaze, artefacts and language, and considers how these modes work together to create meanings in a 'multimodal ensemble' (NCCA, 2012).

Theories relating to multimodality have challenged the privileging of language in the education system especially in the early years. Communication has always been multimodal. That is, humans make meaning through various modes, including images and gestures but schooling has focused primarily on oral and written language. There is a need to attend to other modes such as gestures when it comes to classroom communication with children with low language skills to enhance literacy acquisition in Early Childhood and Primary Education (Kress, 2003; 2010; Pahl, 2009; Rowe, 2008; Lancaster 2001). The attention of this study is on literacy because it is the bedrock of other subjects.

Research in early years in classrooms suggests that children are engaged in multimodal production and analysis in unofficial activities (Björkvall \& Engblom, 2010), and that teachers need to draw on their skills and knowledge in order to embed multimodality in the official literacy curriculum (Flewitt, 2011; Wolfe \& Flewitt, 2010).

\subsection{Gestures as Comprehension Enhancement}

Communication normally takes place at the nonverbal level. According to Behjat, Bayat \& Kargar (2014), nonverbal Communication takes various forms, one of which is oral or speech. They observed that when people speak, they normally do not confine themselves to the mere emission of words. They also use their hands or gestures, head movements, eye contact, through smiling, body postures and symbols to communicate.

Gesture is a form of non-verbal communication made with 
a part of the body, used instead of or in combination with verbal communication. Gesture is sometimes used to refer to any of a variety of movements including movement of hands and arms, adjustment of posture, the touching of oneself (e.g., stroking one's hair), various (nervous) ticks, and other fiddling movements that people use while talking (Kendon, 1996). Different gestures have different meanings. Gestures constitute a central feature of human development, knowing, learning, and communication across cultures (Roth, 2001; Kendon, 1997; Levinson, 1997); even congenitally blind individuals' gesture when they communicate (Iverson \& Goldin-Meadow, 2005).

Gestures play an important role in learning, development, and communication of children (Piaget, 1959). Research has it that children's understanding of the significance of gestures would benefit them in meaning making; therefore competence should include gesture awareness (McCafferty, 2008). Early research show that almost all the rules children verbalize while explaining a board game to an adult are accompanied by gestures; the gestures provide cognitive support when children attempt to talk about difficult tasks (Evans \& Rubin, 1979). This means that if teachers combine gestures with verbal communication, early learners' literacy acquisition will be improved tremendously, thereby helping children to succeed in their future academic endeavours (Muramoto, 1999).

The use of gestures is a universal feature of human communication. Numerous studies have proved that gesture plays a role in speech production, word retrieval, cognitive activity, learning, and memory (Carahaly, 2012). Children who gesture during learning retain the knowledge gained from instruction better than children who do not use gesture (Cook, Mitchell, \& Goldin-Meadow, 2008; Krauss \& Morsella, 2002).

Studies that looked at gestures used by children proved that they are important in accessing stored knowledge. It has been revealed that children who are instructed to gesture while recalling an event are able to report more details about the event compared to children who do not have that opportunity and are made to use just oral language. Gesturing clearly enhances the overall performance of the memory process (Stevanoni \& Salmon, 2005; Alibali, Kita \& Young, 2000; Xu et al., 2009; Bernardis \& Gentilucci, 2006).

\subsection{Meaningful Gestures}

McNeil (1992) offers four different categories for gestures in spontaneous interaction:

1) Iconic gestures: These depict the content of speech, both objects and actions, in terms of their physical characteristics. In other words, Iconic gestures are closely linked to the semantic content (i.e., the lexical components) of the talk (see also Schegloff, 1984). Iconic gestures may be: kinetographic, representing some bodily action, like walking fast, or pictographic, representing the actual form of an object, like outlining the shape of an object. Iconic gestures are the different from other gestures in that they are used to show physical concrete items. They are useful in such a way that they add detail to the mental image that a person is trying to convey. They also show the first person or second person point of view/ view point that the person is taking.

2) Metaphoric gestures: Similar to iconic gestures, these gestures may be kinetographic or pictographic, but they represent an abstract idea rather than a concrete object or action. That is when using iconic gestures a concept (an abstract entity) is being explained. Gestures are in three dimensional spaces and are used to shape an idea being explained either with specific shapes such as finger pinches and physical shaping or more general waving of hands that symbolizes that complexity of what is being explained.

3)Deictic gestures: These are pointing gestures which indicate either concrete entities in the physical environment, or abstract loci in space. Deictic gestures can be either actual or metaphoric. For example, we may point to an object in the immediate environment, or we may point behind us to represent past time.

4) Beat gesture: These are gestures in which the hand moves with a rhythmical pulse that lines up with the stress peaks of speech. A typical beat gesture is a simple flick of the hand or fingers up and down, or back and forth; the movement is short and fast. Although beats may serve a referential function, their primary use is to regulate the flow of speech (Schegloff, 1984; Taleghani-Nikazm, 2008). We call these categories of gestures, meaningful gestures. Beating and repetition plays to primitive feelings of basic patterning and can vary in sense according to the context. The beat creates emphasis and graphs and grabs attention.

\section{Methodology}

The study was a case study in which observation and interviews were used to gather data from the selected Early Childhood Education (ECE) Centres in the Cape Coast Metropolis in the Central Region of Ghana. Participant observation was used to enable the researchers have first hand information regarding the use of gestures alongside verbal communication in literacy instructions. The observation was done by both researchers with language/literacy studies and applied linguistics background. All the classrooms were observed by both researchers at the same time. As explained above, the observation was based on how teachers used gestures as described by McNeil (1992) alongside speech in their literacy instruction. Interview (semi-structured) was also used to crosscheck data from the observation. Both researchers did the interview together (One did the oral interview and the other took the notes). Purposive sampling technique was used in the selection of the subjects. There are uncountable Early Childhood Education centres in the Cape Coast Metropolis. Most of them are private. The private ones normally start from Crèche, Nursery 1 and 2, and KG 1 and 2. In the private schools the children can start pre-school as early as 3 months. 
Such schools are usually called Day Care Centres. The public school centres are normally KG 1 and 2 where the children start at age 4 . Each level of class normally has about 2 teachers and attendants. Sometimes the number of teacher and attendants depend on class enrolment.

In all, 10 Early Childhood Education centres, made up of five public and five private schools in the Cape Coast Metropolis were used. Cape Coast, the capital city of the Central Region of Ghana was selected as the research area because it is noted as the centre of education in Ghana. It has the oldest Secondary school and also most of the renowned schools in the country. It has quite a number of schools more than most towns and cities in Ghana. In each of the schools, only nursery and KG classes were chosen because the focus of the study was on the literacy acquisition of the very young learners. Before we went to the schools, we wrote to them to seek their consent, which they gave us the nod. Each school was observed once a week for eight weeks. We selected one classroom per school to observe. In all, 10 centers made up of 1 Nursery 1, and 9 KG 1 and 2 classrooms were observed. We joined the selected classes in the classroom or play grounds where the various lessons were taught. The observation was conducted with an observation guide. Our major interest was the use of meaningful gestures in lesson delivery. We interviewed the teachers observed. Mixed methods were used to analyse the data. Descriptive statistics was used to analyze the quantitative data while the qualitative data were grouped according to themes and patterns. SPSS version 16 was used to find the mean of the rating and also used to draw the graph

\section{Discussion of Findings}

The findings of the study were categorized according to the research questions.

\subsection{Experience ECE Teachers Have in Teaching Literacy}

The first research question sought to find out the experiences the ECE teachers had acquired to teach literacy. The results from the interview showed that most private school teachers had little knowledge about literacy. Out of the five teachers in the private schools, only one had a Diploma in ECE. The other four who had West African Senior Secondary Certificate of Education (WASSCE) as their highest level of education did not have any professional experience so far as teaching of literacy is concerned. However, in the public schools, it was found out that only one teacher was a Certificated 'A' teacher. Two teachers had Diploma in Basic Education as the other two had Bachelor of Education Degree in Basic Education. This indicates that teachers in the public schools are more professionals than their counterparts in the private schools. The question that emerges from this is if the public schools have better qualifications than those in the private schools, then how come the performance of private schools are better than the public schools? This shows that, supervisions, monitoring and other factors come in when it comes to teaching and learning in schools. During our interviews, it became clear that supervision in private schools is more intensive than the public schools. In the public schools, most of the teachers know what to do but feel reluctant to give their best.

In terms of the number of years taught in ECE centres, teachers in private schools range between one to six years. When asked why they spend few years at the private schools, they commented that they mostly use that place as a transit. Other reasons were that, some went there because they were waiting for their WASSCE results; to better their results; as a solution to their economic needs and so some left at the slightest opportunity somewhere. At the public schools, it was realized that teachers stayed longer. For instance, the result indicated that the number of years that teachers spent at ECE public school ranged from three to ten years. This was because it was their chosen profession and also felt more secured because they were paid by the central government and the condition of service was sometimes better than some private schools. This shows that in terms of qualification and experiences, public school teachers who teach in $\mathrm{KG}$ used for the study are far ahead of their counterpart in the private schools.

One notable issue was that most of the teachers in the public early childhood centres are females and they are either wives or relatives of lecturers teaching in the University of Cape Coast, policemen who are on transfer to Cape Coast, or other public servants working in and around the Cape Coast Metropolis. Most of these spouses or relatives have overstayed in such schools for long and that they have become redundant in such schools, hence, their inability to perform better in such centres.

\subsection{The Emergent Literacy Behaviours Learners Bring to School}

The second research question was to find out teachers' knowledge about the emergent literacy behaviours young children bring to school. The results showed that out of the 10 respondents, as high as $8(80 \%)$ of them did not even know what emergent literacy behaviour are, as a result, they could not identify them in children. Out of the 10 respondents, only 2 were able to provide some answers to the questions asked at the first instance. Upon further explanations, the answers that were given were pretend reading, scribbling and drawing.

This is surprising because before a child goes to school, there is some emergent literacy behavior he or she exhibits even in the house. Sometimes the child is seen to be opening books, writing or scribbling with anything he or she lays hands on. The children writes or scribbles on walls, floor, tables, books, sand, and so on. Before teaching, teachers must know these to guide them in their teaching. We suggest that, the Ghana Education Service and the Ministry of Education in Ghana take notes of this and organize series of workshops for the early childhood teachers to learn more about the emergence literacy behavious of these children in order to use meaningful gestures alongside speech in teaching them. This will help build proper education foundation for the children. 


\subsection{The Extent to Which Teachers use Gestures in Teaching Literacy}

This was mainly based on the observation data to find out the extent to which ECE teachers use gestures to teach literacy. The findings were categorized under literacy oriented lessons. These include reading, recitation, storytelling, community circle time, listening and speaking. Worship was later added due to its peculiar nature, in that learners need the concepts taught to mould their lives. Almost all the Basic Schools in Ghana have 'worship' time once in the week, usually on Wednesdays. They mainly sing, dance, and share the word of God during the worship time. The observation was guided by the rubrics below:

Table 1. Rubrics for Observation Data.

\begin{tabular}{lll}
\hline Rubrics & Rating & Interpretation \\
\hline Excellent (E) & $4.6-5$ & Those who used gestures meaningfully throughout the lesson delivery. \\
Very Well (VW) & $3.6-4.5$ & Those who used gestures meaningfully most times in the lesson delivery. \\
Well (W) & $2.6-3.5$ & Those who used gestures meaningfully sometimes in the lesson delivery \\
Fairly Well (FW) & $1.6-2.5$ & Those who partially used gesture meaningfully in the lesson delivery \\
Not at all (N) & $0.5-1.5$ & Those who did not use meaningful gestures in the lesson delivery at all. \\
--- & 0 & The subject was not seen teaching. \\
\hline
\end{tabular}

Table 2. Observation Data.

\begin{tabular}{lllllll}
\hline Type of School & Reading & Recitation & Story Telling & Community Circle Time & Listening \& Speaking \\
\hline PR 1 & FW & E & W & FW & N & FW \\
PR 2 & N & VW & FW & FW & FW \\
PR 3 & FW & VW & FW & - & FW & N \\
PR 4 & FW & E & W & FW & FW & FW \\
PR 5 & FW & VW & FW & FW & FW & N \\
PU 1 & N & VW & FW & - & FW \\
PU 2 & N & VW & FW & FW & N \\
PU 3 & N & VW & FW & FW & N \\
PU 4 & N & VW & FW & FW & N \\
PU 5 & N & W & FW & N \\
\hline
\end{tabular}

Code

Private Schools - PR

Public Schools - PU

From Table 2, it could be seen that teaching in 4 schools made up of teachers in 3 private and 1 public schools fairly used gestures alongside speech to explain things to learners. Teachers in the remaining six schools did not use gesture at all in the teaching of reading during the observation. For recitation, teachers in all the ten schools visited used gestures very well teachers in two schools were outstanding in the use of recitations. This made the recitation lessons very interesting and participatory. In Storytelling lessons, almost all the teachers in the schools observed used gestures fairly well with teachers in 2 private schools using them well. Teachers in these 2 schools in addition to the gestures, used other prosodic features like tone variation and stress to enhance comprehension.

For Community circle time, all the teachers observed used gestures fairly well while 3 of them did not use them at all. In listening and speaking lessons, 4 private schools used gestures fairly well with 1 not using them at all. In the public schools only 2 teachers used gestures fairly well, with 2 teachers not using them at all in their lesson delivery. The result also showed that 'worship' was the programme that teachers scarcely used gestures. Only 2 teachers in private schools used them fairly well during worship. This indicates that most of the schools delivered their messages through only verbal communication. It was only when they were singing and dancing that some gestures were added. Figure 1 and 2 below show how gestures are being used in teaching all the six areas outlined in private and public schools respectively.

Table 3 and figure 3 below interpret how gestures were used by teachers in private and public schools respectively. For reading, teachers in private schools used gestures averagely with the mean of 1.8 which is in the range of fairly well (see rating at Table 1). This means that teachers in those centres partially used gesture meaningfully in their lesson delivery, whilst their counterparts in the public schools did not use meaningful gestures in their teaching. On the average, ECE teachers did not properly use meaningful gestures in teaching reading. Again, on recitation, it was clear that teachers spent their time and energy to use meaningful gestures very well, but still did not attain an excellent mark. Teachers in private schools were more effective in the use of gestures during recitation lessons. Meaningful gestures as used by both teachers in private and public schools in storytelling, community circle time, listening and speaking lessons were fairly well, which is not encouraging. As for 
worship, the teachers did not use meaningful gestures in the lesson delivery at all.

Table 3. Gestures as Used in Private and Public Schools.

\begin{tabular}{llll|lll}
\hline Types of School & Reading & Recitation & Storytelling & Community Circle Time & Listening and Speaking \\
\hline Private & 1.8 & 4.4 & 2.4 & 2 & 1.8 & Worship \\
Public & 1.2 & 3.8 & 2.0 & 2 & 1.4 & 1 \\
Total & 1.5 & 4.1 & 2,2 & 2 & 1.6 \\
\hline
\end{tabular}

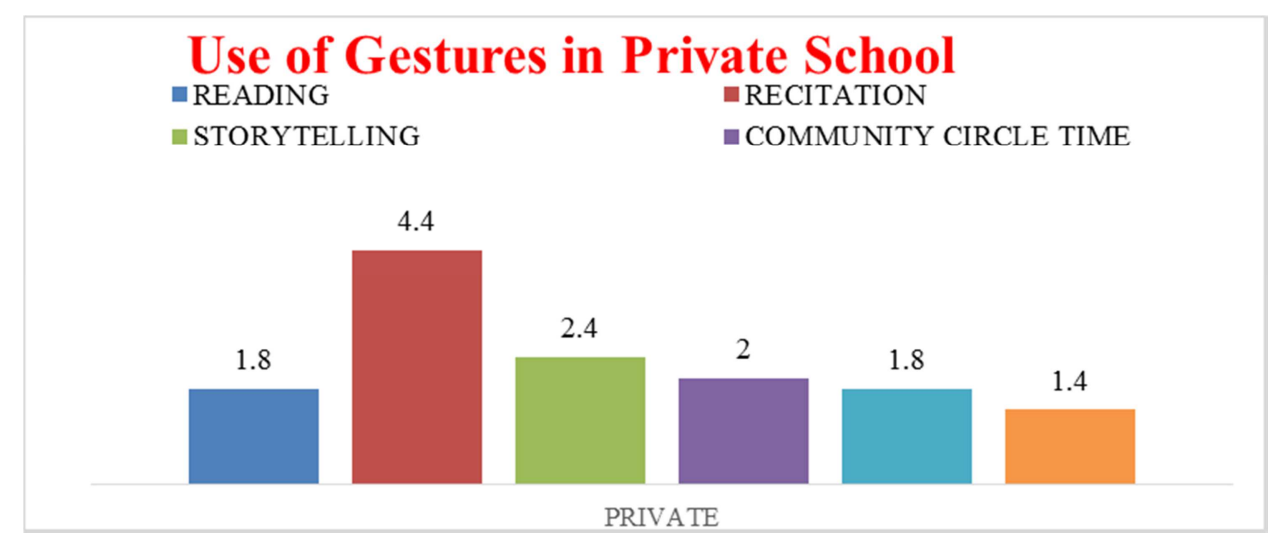

Figure 1. Showing the use of gestures in private schools.

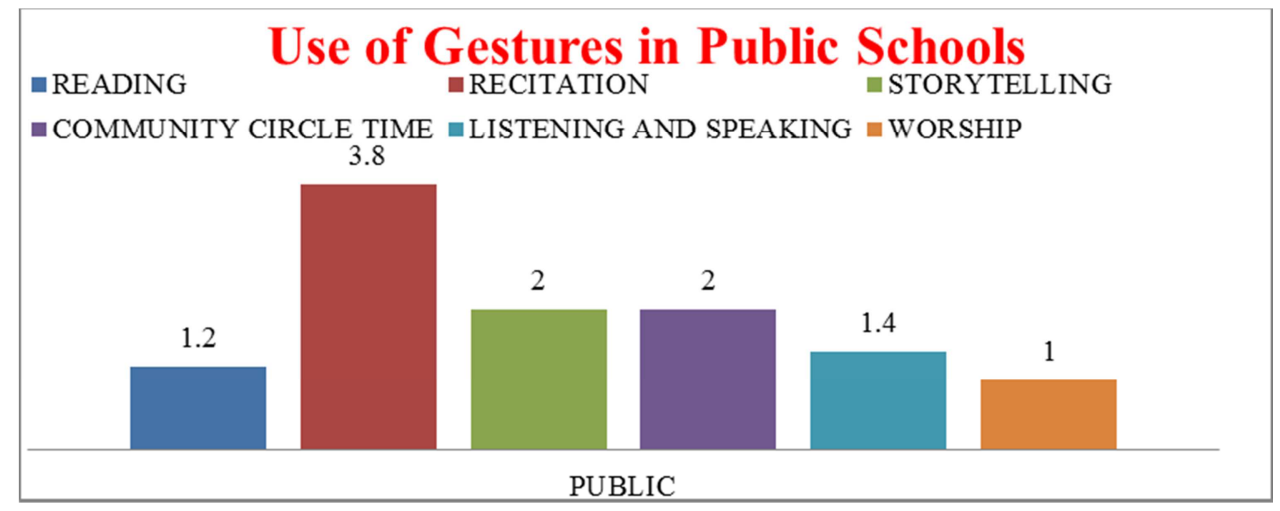

Figure 2. Showing the use of gestures in public schools.

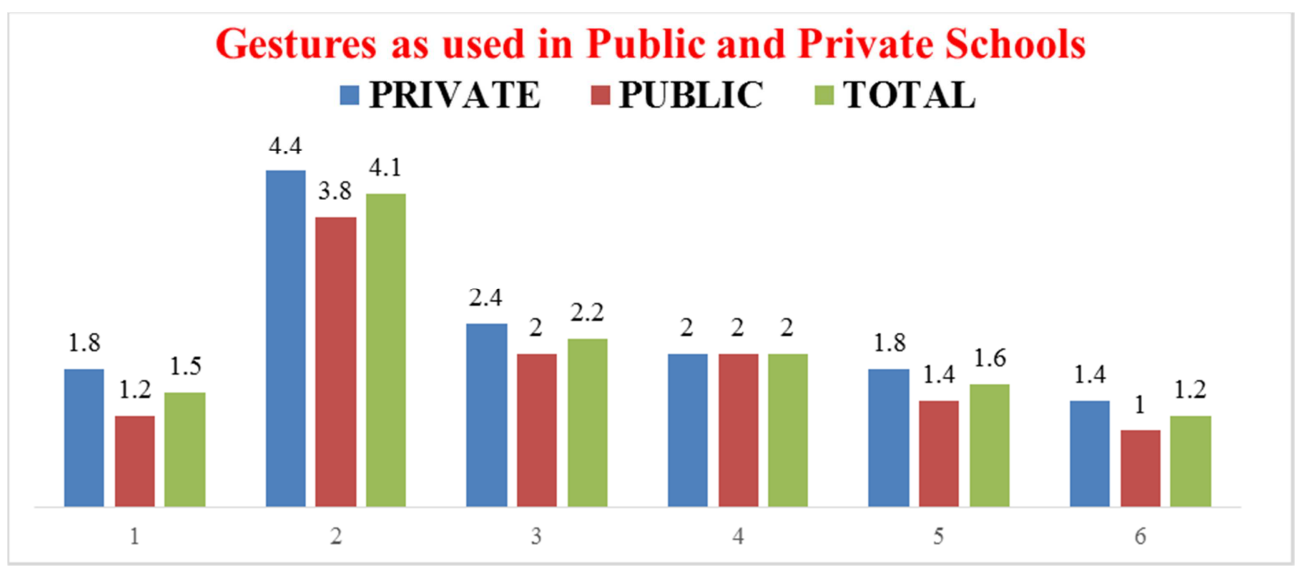

Figure 3. Showing gestures as used in public and private schools.

\footnotetext{
Code

1 - Reading

2- Recitation

3 - Story Telling

4 - Community Circle Time

5 - Listening \& Speaking

6 - Worship
} 
In order to confirm the result from the observation, the teachers observed were interviewed to check whether all their pupils could speak fluently. The response to this question showed that not all children could use language effectively at the early years. A follow up question which sought to examine what teachers did to help young learners to understand what they taught was asked. Almost all of the respondents said they added body language to the verbal communication. This was followed by a question to specify the actual body language used. The respondents confirmed that they used gestures alongside speech in their instruction to enhance children's understand of what they taught. When respondents were asked to tell literacy lessons in which they used gestures their responses were in line with the result from the observation. Lessons mentioned were recitation, storytelling and community circle time. 'Recitation' was the prominent subject that was mentioned by all the respondents.

\subsection{How Gestures Enhance Teaching and Learning of Literacy in the Ece Classroom}

This research question was to find out how gestures enhanced literacy acquisition in the classroom. All the respondents said it helps pupils especially those who did not have enough language to express their thought. Some of the teachers had this to say:

"The pupils use it to help adults understand what they want to say" (Nursery teacher)

"I use gestures alongside verbal communication to enable pupils understand what I am teaching" (KG 1 teacher)

Some teachers were of the view that the use of gestures enhanced classroom interaction thereby hastening pupils' language development. They also said it made teaching and learning interesting. All the respondents said it helped pupils, especially those who did not have enough language to express their thought. Also, gestures help teachers to make their explanation clearer to the pupils. When respondents were asked whether they would advise ECE teachers to use meaningful gestures alongside verbal communication in their entire lesson, they all responded in the affirmative and the reasons for their answers included the following:

1 It promotes interactive and fully participated lessons.

2 It enhances language development.

3 It enhances comprehension.

4 It makes teaching and learning interesting.

This result is in line with McNeil, (1992); Schegloff, (1984); Taleghani-Nikazm (2008) that meaningful gestures enhance classroom interaction, fosters comprehension as well as hastening language development.

\section{Conclusion}

The study explored the power of meaningful gesture in improving early children literacy learning. The analysis indicated that the use of gestures alongside speech promoted comprehension as children grasp the meaning of concepts and improved their understanding with age. Overall, the study highlighted the important role meaningful gestures play in language comprehension as children learn to unpack increasingly complex communications addressed to them at the early years. On the whole, the study revealed that, private school teachers who were mostly untrained used meaningful gestures in their teaching better than their counterparts in the public schools who were trained.

Based on the findings, it can be concluded that most of the teachers and the attendants were not conversant with the emergent literacy behaviours pupils bring to schools. Also, most teachers used meaningful gestures mainly during recitation but scarcely used them in other literacy lessons. Moreover, teachers knew the importance of meaningful gestures in lessons but lacked the expertise in their usage in other aspects of literacy instruction.

\section{Recommendation}

It is recommended that teachers at the ECE who do not have the requisite qualification should try as much as possible to enroll in Sandwich and Distance ECE programmes in the universities, especially University of cape Coast, and University of Education, Winneba, all in Ghana to upgrade them to enable them work effectively. Training institutions like Colleges of Education, Universities and other training centres should include the appropriate use of meaningful gestures in their training programmes for ECE teachers.

Also, headteachers and proprietors / proprietresses should organize regular in-service training to equip teachers adequately on the use of meaningful gestures as they mostly handle pupils who are developing language.

\section{Acknowledgement}

Many people contributed immensely to the success of this article. First and foremost, we are grateful to all the head teachers of the selected schools and the teachers who participated in this study for their effort. We appreciate the organizers of 2013 Conference of the Collaboration of Education Faculties in West Africa (CEFWA), where we had the privilege to present this paper in September, 2013. We are also indebted to the late Prof. Jonas Nartey Akpanglo-Nartey (Nene Akpanglo Abanam II) for nurturing us from the undergraduate level, through M. Phil. We were his Teaching Assistants, Department of Applied Linguistics, Faculty of Modern Languages, University of Education, Winneba, Ghana, for two years. He was also our principal supervisor at the M. Phil level in the Department of Applied Linguistics, in the same university. Our thanks go to anybody who in diverse ways contributed to the success of this paper. 


\section{References}

[1] Abdolmanafi-Rokni, S. J. and Qarajeh, M. (2014). Digital Storytelling in EFL Classrooms: The Effect on the Oral Performance. International Journal of Language and Linguistics. Vol. 2, No. 4, 2014, pp. 252-257. doi: $10.11648 / \mathrm{j} . \mathrm{ij} 11.20140204 .12$

[2] Alibali, M. W., Kita, S., \& Young, A. J. (2000). Gesture and the process of speech production: We think, therefore we gesture. Language and Cognitive Processes, 15(6), 593-613.

[3] Barnett, W. S. (1995). Long-term effects of Early Childhood Programs on Cognitive and School Outcomes. The Future of Children, 5, 25-50

[4] Behjat, F. Bayat, S. \& Kargar, A. A. (2014). An Investigation of Students' Attitudes on Teachers' Nonverbal Interaction in Iranian EFL Classrooms. International Journal of Language and Linguistics. Special Issue: Innovations in Foreign Language Teaching. Vol. 2, No. 6-1, 2014, pp. 13-18. doi: 10.11648/j.ijll.s.2014020601.13

[5] Bernardis, P., \& Gentilucci, M. (2006). Speech and gesture share the same communication system. Neuropsychologia, 44, 178-190.

[6] Björkvall, A., \& Engblom, C. (2010). Young children's exploration of semiotic resources using unofficial computer activities in the classroom. Journal of Early Childhood Literacy10(3), 271-293.

[7] Carahaly, L. (2012, March 8-9). Using Symbolic Gestures to Facilitate Speech Motor Planning \& Literacy Development. Texas Speech-Language-Hearing Association Conference, San Antonio, TX.

[8] Collins, M. F. (2010). ELL preschoolers' English vocabulary acquisition from storybook reading. Early Childhood Research Quarterly, 25(1), 84-97.

[9] Cook, S.W., Mitchell, Z., \& Goldin-Meadow, S., (2008). Gesturing makes learning last. Cognition. 106(2), 1047-1058

[10] Crayner, J. B. (1969), Yeehyiahyia oo! Bureau of Ghana Languages, Accra, Ghana

[11] Evans, M. A., \& Rubin, K. H. (1979). Hand gestures as a communicative mode in school- Aged children. The Journal of Genetic Psychology, 135, 189-196.

[12] Flewitt, R. S. (2011). Bringing ethnography to a multimodal investigation of early literacy in a digital age. Qualitative Research, 3, 293-310

[13] Frede, E. (1995). The role of program quality in producing early childhood program benefits. The Future of Children, 5, 115-132.

[14] Gregory, A. E. \& Cahill, M. A. (2010). Kindergarteners can do it, too! Comprehension strategies for early readers. The Reading Teacher, 63, 515-520.

[15] Holtzheuser, S. McNamara, J. Short, A. \& Keay, C. (2012). Reading Rocks Junior: An Exploratory Study of an Emergent Literacy Program for Children at-Risk for Learning Disabilities. International Journal of Elementary Education. Vol. 1, No. 1, 2012, pp. 1-7. doi: 10.11648/j.ijeedu.20120101.11
[16] Hall, N. R. (1987). The Emergence of Literacy. Portsmouth, NH: Heinemann.

[17] International Reading Association and National Association for the Education of Young Children. (1998). Learning to read and write: Developmental Appropriate Practices for Young Children. Young Children, 63(4), 30-46

[18] Iverson, J. M., \& Goldin-Meadow, S. (2005). Gestures pave the way for development (online article). Department of Psychology. University of Chicago; Association for Psychological Science Inc.

[19] Kendon, A. (1996). An agenda for gesture studies. Semiotic Review of Books, 7, 8-12.

[20] Kendon, A. (1997). Gesture. Annual Review of Anthropology, 26, 109-128.

[21] Krauss, R. M., \& Morsella, E. (2002). Movement Facilitates Speech Production: A Gestural Feedback Model. Columbia University

[22] Kress, G. (2003). Literacy in the new media age. London: Routledge.

[23] Kress, G. (2010). Multimodality: A social semiotic approach to contemporary communication. London: Routledge.

[24] Lancaster, L. (2001). Staring at the page: the function of gaze in a young child's interpretation of symbolic forms. Journal of Early Childhood Literacy, 1( 2), 31-152

[25] Levinson, S. (1997). Language and cognition: The cognitive consequences of spatial description in Guugu Yimithirr. Journal of Linguistic Anthropology, 7, 98-131.

[26] McCafferty, S. G., \& Gale, S. (2008). Gesture: Second Language Acquisition and Classroom Research. London: Routledge

[27] McNeill, D. (1992). Hand and mind: What gestures reveal about thought. Chicago: University of Chicago Press.

[28] Morford, M., \& Goldin-Meadow, S. (1992). Comprehension and production of gestures in Combination with speech in one-word speakers. Journal of Child Language, 19, 559-580.

[29] Muramoto, N. (1990). Gesture in Japanese Language instruction: The case of error correction. In L. K. Heilenmann (Ed.), Research issues and Language Program Direction, (pp. 143- 175). Boston: Heinle \& Heinle.

[30] National Council for Curriculum and Assessment (NCCA 2012). Literacy in Early Childhood and Primary Education. 24, Merrion Square, Dublin 2.

[31] National Reading Panel (2000). Teaching Children to read: An Evidenced-based assessment of Scientific research literature on reading and its implications for reading instruction. Washington, DC: US Department of Health and Human. Services

[32] Pahl, K. (2009). Interactions, intersections and improvisations: Studying the multimodal texts and classroom talk of six- to seven-year-olds. Journal of Early Childhood Literacy, 9(2), $188-210$.

[33] Piaget, J. (1959). The Language and thought of the child. London: Routledge \& Kegan Paul 
[34] Roth, W. M. (2001). Gestures: Their Role in Teaching and Learning". American Educational Research association, 71(3), 365-392

[35] Rowe, D. (2008). The social construction of intentionality: two year olds and adults participation at a preschool writing center. Research in the Teaching of English, 42(4) 387-434.

[36] Schegloff, E. A. (1984). On some gestures' relation to talk; in J. M. Atkinsons and J. Heritage structures of social interaction (pp. 266-296). Cambridge: Cambridge University Press

[37] Snow, C. E., Burns, S., \& Griffin, P. (Eds.) (1998). Preventing Reading Difficulties in Young Children. Washington, DC: National Academy Press.

[38] Stanfield, C., Williamson, R., \& Özçalışkan, Ş. (2013). How early do children understand gesture-speech combinations with iconic gestures? Journal of Child Language, 1-10.

[39] Stevanoni, E., \& Salmon, K. (2005). Giving memory a hand: Instructing children to gesture enhances their event recall. Journal of Nonverbal Behavior, 29, 217-233.

[40] Svensson, A. S. (2014). Circle Time in Pre-School Class: A Study about Sex-Year-Old Children and Their Experiences of Participation in Two Different Circle Times. International Journal of Elementary Education. Vol. 3, No. 4, 2014, pp. 98104. doi: $10.11648 /$ j.ijeedu.20140304.12
[41] Taleghani-Nikazm, C. (2008). Gestures in Foreign Language Classroom: An Empirical Analysis of their Organization and Function. Proceedings of the 2007 Second Language Research Forum, Melissa Bowles et al., (ed.). 229-238. Somerville, MA: Cascadilla Proceedings Project.

[42] Vukelich, C., Christie, J., \& Enz, B, (2012). Helping young children learn language and literacy: Birth through Kindergarten $\left(3^{\text {rd }}\right.$ Ed.) Boston: Pearson

[43] Walsh, M. (2010). Multimodal literacy: Researching classroom practice. Sydney:e:lit

[44] Whitehurst, G. J., \& Lonigan, C. J. (2001). Emergent literacy: Development from prereaders to Readers. In S. B. Neuman\& D. K. Dickinson (Eds.), Handbook of early literacy Research, (pp. 11-29). New York, NY: Guilford Press.

[45] Wolfe, S. and Flewitt, R. S. (2010). New technologies, new multimodal literacy practices and young children's metacognitive development. Cambridge Journal of Education, 40(4), 387-399.

[46] Xu, J., Gannon P. J., Emmorey, K., Smith, J. F., \& Braun, A. R. (2009). Symbolic gestures and spoken language are processed by a common neural system. Proc Natl AcadSci U S A. 106:20664-20669. doi:10.1073/pnas.0909197106 PMID 19923436 